\title{
Ludwig Angina in Pregnancy: Treatment Outcome in 12 Patients and Review of Literature
}

\author{
Ibraïma Traoré ${ }^{1}$, Rasmané Béogo ${ }^{1,}$, , Toua Antoine Coulibaly ${ }^{1}$, Der Adolphe Some ${ }^{2}$, \\ Alain Ibrahim Traore ${ }^{3}$, Gandaaza Euthyme Armel Poda ${ }^{4}$ \\ ${ }^{1}$ Department of Stomatology and Maxillofacial Surgery, Université Nazi Boni, Bobo-Dioulasso, Burkina Faso \\ ${ }^{2}$ Department of Obstetrics and Gynecology, Université Nazi Boni, Bobo-Dioulasso, Burkina Faso \\ ${ }^{3}$ Department of Anaesthesiology and Intensive Care, Université Nazi Boni, Bobo-Dioulasso, Burkina Faso \\ ${ }^{4}$ Department of Infectious Disease, Université Nazi Boni, Bobo-Dioulasso, Burkina Faso
}

\section{Email address: \\ rbeogo@yahoo.fr (R. Béogo) \\ ${ }^{*}$ Corresponding author}

\section{To cite this article:}

Ibraïma Traoré, Rasmané Béogo, Toua Antoine Coulibaly, Der Adolphe Some, Alain Ibrahim Traore, Armel Poda. Ludwig Angina in Pregnancy: Treatment Outcome in 12 Patients and Review of Literature. International Journal of Clinical Oral and Maxillofacial Surgery. Vol. 5, No. 1, 2019, pp. 5-9. doi: 10.11648/j.ijcoms.20190501.12

Received: November 6, 2018; Accepted: January 25, 2019; Published: March 11, 2019

\begin{abstract}
Ludwig angina is a rare but severe life-threatening cellulitis, classically of odontogenic origin, characterized by an extensive and a rapidly progressive inflammation of subcutaneous tissue of the face and severe systemic toxicity. Its prognosis is potentially worse in pregnancy given the higher vulnerability of both mother and fetus to infection and to the consequences of therapies. Early diagnosis and timely treatment are of paramount importance in the prognosis of this condition but could be however challenging as it is infrequently observed in current daily practice. Moreover, literature dealing with Ludwig's angina in pregnancy is scarce, consisting mostly in isolated case reports from developed countries. The aim of this article was to improve awareness on Ludwig angina in pregnancy through a report of experience in 12 patients and a literature review on the diagnosis and treatment of this clinical entity. To this end, medical records of 12 patients with Ludwig angina in pregnancy were analysed retrospectively and the diagnosis and treatment approaches discussed through a literature review. Age of pregnancy ranged from 27 to 37 weeks. In all the patients, the cellulitis origin was a carious molar of the mandible. The infection spread extended to the neck (4 patients), the thorax ( 3 patients) and the temporal fossa (2 patients). One patient presented with necrotizing fasciitis extending from the submandibular and submental regions to the thorax. Bacteriological examination of pus which was possible and successful in 4 patients only, showed staphylococcus aureus (2 patients) staphylococcus SP (1 patient) and staphylococcus epidermidis ( 1 patient). Death occurred in 2 mothers and in 7 fetus giving mortality rates of $16.7 \%$ and $58.3 \%$ respectively. Direct causes of death in mothers were sepsis shock and air way compromise. In 6 out of the 7 mothers who had dead fetus, the infection extended beyond the mouth floor. Oral health care providers should be aware for proper treatment of dental infections. They should also be alert for early recognition and multidisciplinary treatment of Ludwig angina in pregnancy in collaboration with obstetricians, specialists of intensive care and infectious diseases.
\end{abstract}

Keywords: Ludwig Angina, Diffuse Cellulitis, Infection in Pregnancy

\section{Introduction}

Infections continue to account for a major cause of maternal, fetal, and neonatal mortality and morbidity in developing countries as well as in the developed world [1]. Ludwig angina is of these, a condition named in reference to the German physician Karl Friedrich Wilhelmvon Ludwig who first described it in 1836. It is classically a poly microbial infection of odontogenic origin characterized by a severe systemic toxicity associated to an extensive and a rapidly progressive inflammation of the subcutaneous tissue which begins at the floor of the mouth and may progress to reach the pharyngeal space, the neck and the thorax $[2,3]$. Although the related mortality rate which exceeded $50 \%$ 
before the 1950 s decreased significantly thanks to modern antibiotic therapies and surgical techniques, current estimates are still in the range of $8 \%[4,5]$. Prognosis may be worse in pregnancy given higher vulnerability of both mother and fetus to infection and to the consequences of therapies. High threat for life in Ludwig's angina imposes early diagnosis and timely treatment. This may be however challenging as the condition is infrequently observed in current daily practice. Furthermore, literature dealing with Ludwig angina in pregnancy is scarce, consisting mostly in isolated case reports from developed countries. This study aims to improve awareness on this clinical entity through a report of experience in 12 patients and a literature review on its diagnosis and treatment.

\section{Methods}

\subsection{Study Design}

This study is carried out at a referral hospital in Burkina Faso. It consisted in a retrospective analysis of the medical records of pregnant women with Ludwig angina and a literature review on the diagnosis and treatment approaches of Ludwig angina in pregnancy. All the patients were subject to the strategies for malaria prevention and control during pregnancy recommended by the WHO in the African region [6]. Ludwig angina assessment included: patient's history; measure of temperature, blood pressure, pulse, heart frequency and respiration frequency, oxygen saturation in room; infection diffusion checking; screening for infection source; laboratory tests comprising full blood count (FBC), blood urea level test, glycaemia, bacteriology of the cellulitis pus. The pregnancy assessment and follow-up were performed by clinical examination and ultrasound at department of obstetrics and gynaecology. The treatment started at the department of anaesthesia and intensive care and continued when the patient's condition improved, at the department of oral and maxillofacial surgery. It consisted of respiratory support by face mask or cannulas; antibiotic therapy consisting in a combination of ceftriaxone $(60 \mathrm{mg} / \mathrm{kg}$ day), metronidazole $(30 \mathrm{mg} / \mathrm{kg}$ day) given intravenously until 2-3 days after normalization of the temperature and gentamycin $(3 \mathrm{mg} / \mathrm{kg}$ day) given during 5 days; incision and drainage of pus collections performed by multiple skin incision and blunt dissection under local anaesthesia; intravenous administration of $2 \mathrm{mg} / \mathrm{kg}$ day of steroids during 2-3 days; administration of $40-60 \mathrm{ml} / \mathrm{kg}$ day of saline serum and isotonic glucose serum; treatment of the source of the infection consisting classically in extraction of carious teeth performed as soon as the mouth opening authorized this. At discharge, patients were prescribed association of amoxicillin and clavulanic acid given orally. The collected data included patient history, cellulitis clinical presentation and germ, outcome in mother and in fetus.

\subsection{Inclusion Criteria}

The patients who were included in this study presented with Ludwig angina and pregnancy. Ludwig angina was defined as extensive inflammation of subcutaneous tissue evolving from the mouth floor and severe sepsis. Patients with evident severe underlying morbidity such as uncontrolled diabetes or gestational toxaemia were not included.

\section{Results}

Patients' characteristics, Ludwig angina extent and its outcome in mother and in fetus are given in table 1. Patients' age ranged from 20 to 35 years (mean 27.3 years). All the patients were at the second or third trimester of pregnancy with age gestation ranging from 18 to 37 weeks. In all the patients, the cellulitis source was a carious molar of the mandible. The infection diffused to the neck (4 patients), the thorax (3 patients) and the temporal fossa ( 2 patients). In one patient necrotizing fasciitis extending from the submandibular and submental regions to the thorax was noted as presented in figure 1. One patient had multiple lung abscesses as illustrated in figure 2 and one other patient had mediastinis. Bacteriological examination of pus was possible and successful in 4 patients, showing staphylococcus aureus (2 patients) staphylococcus SP (1 patient) and staphylococcus epidermidis (1 patient). Death occurred in 2 mothers and in 7 fetus, giving mortality rates of $16.6 \%$ and $58.3 \%$ respectively. In 2 fetus, death was associated to mother death. In 6 out of the 7 mothers who had dead fetus, the cellulitis extended beyond the mouth floor. In mothers, death was due to septic shock in the patient with necrotizing fasciitis and air way compromise and shock at hospital admission in another patient.

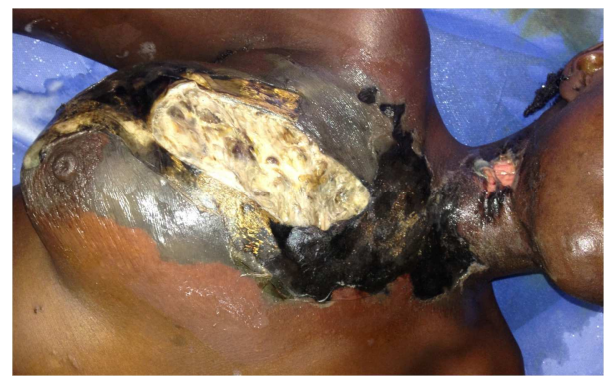

Figure 1. Extensive necrosis extending from submandibular and submental regions to the thorax in a Ludwig angina patient at postpartum.

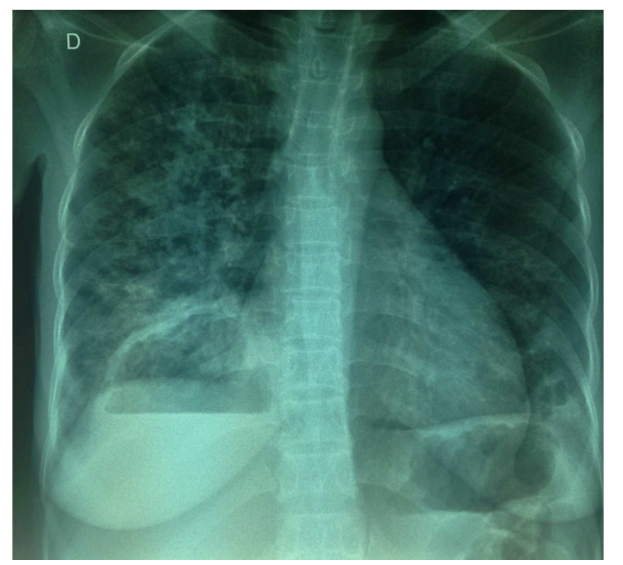

Figure 2. Pneumopathy and multiple lung abscesses in Ludwig angina in pregnancy. 
Table 1. Patients' characteristics, Ludwig angina extent and its outcome in mother and in fetus.

\begin{tabular}{|c|c|c|c|c|c|}
\hline Case & Patient's age & Age of gestation & Cellulitis spread & Outcome in mother & Outcome in fetus \\
\hline 01 & 27 years & 19 weeks & Mouth floor & Favorable & Alive birth \\
\hline 02 & 25 years & 18 weeks & Mouth floor & Favorable & Alive birth \\
\hline 03 & 28 years & 28 weeks & Mouth floor & Favorable & Stillborn \\
\hline 04 & 20 years & 36 weeks & Mouth floor and left temporal fossa & Favorable & Stillborn \\
\hline 05 & 31 years & 28 weeks & Mouth floor, neck and thorax & Death & Death in utero \\
\hline 06 & 26 years & 37 weeks & Mouth floor, neck and thorax & Favorable & Stillborn \\
\hline 07 & 27 years & 28 weeks & Mouth floor and neck & Favorable & Alive birth \\
\hline 08 & 35 years & 37 weeks & Mouth floor and temporal fossa & Favorable & Stillborn \\
\hline 09 & 30 years & 36 weeks & Mouth floor & Favorable & Alive birth \\
\hline 10 & 27 years & 28 weeks & Mouth floor, neck and lung abscess & Favorable & Stillborn \\
\hline 11 & 30 years & 32 weeks & Mouth floor and neck & Death & Death in utero \\
\hline 12 & 22 years & 35 weeks & Mouth floor & Favorable & Premature delivery \\
\hline
\end{tabular}

\section{Discussion}

Ludwig angina as a life-threatening emergency must be recognized early. Patient is typically an individual of 20 to 60 years of age and uncommonly a child who presents with alarming vital signs such as drop of the blood pressure, speedy pulse, and drop of oxygen saturation. A diffuse swelling invades the submandibular, submental and sublingual spaces with the tongue displaced in a superior and posterior position. Extra oral palpation of this swelling may be crepitus, suggestive of infection by anaerobic germs. When it is not treated, the inflammation extends rapidly to the neck, causing dysphagia, dyspnea and even respiratory distress. Further diffusion may lead to the thorax with mediastinis, pleurisy or pericarditis. Though infrequently and as noted in this study, the infection course may progress to necrotizing fasciitis characterized by extensive necrosis of fascia and overlying skin $[7,8]$. Necrotizing fasciitis carries a mortality rate as high as $50 \%$ [9]. In surviving patients, reconstructive surgery may be required to repair soft tissue loss. Trismus makes challenging intra oral examination which frequently shows an odontogenic origin of the infection as noted in all the patients in this study. This is classically an untreated carious tooth of the second or the third mandibular molar [10-11]. From the roots of these teeth which are close to the insertion of the mylohyoid muscle, a periapical abscess following caries progresses to invade successively the thin inner cortex of mandible, the posterior margin of the mylohyoid muscle and the submandibular space. Other sources of the infection reported in the literature include teeth fractures, pericoronitis of wisdom tooth, compound mandibular fractures, submandibular salivary gland sialadenitis, pharyngeal or tonsilar infections, and injuries of the chin skin, mouth floor or tongue [10-12-1314]. Ludwig angina is commonly a polymicrobial infection due to microorganisms of the normal flora of oral cavity [1015-16]. Most commonly involved pathogens include Staphylococcus, Streptococcus, and Bacteroides species [1617]. Laboratory tests may miss however to identify any pathogen because of antibiotics given prior to these tests or to the well-known difficulties of identification of anaerobic germs. Untreated Ludwig angina leads to mortality close to
100 percent, both from the acute sepsis and from airway obstruction making respiratory support and sepsis control the foundation of treatment for patients with this condition [12]. Traditionally, securing the airway by endotracheal intubation or tracheostomy was regarded as the norm [18]. However, nasotracheal intubation requires skill and experience given the diffuse edema which narrows the respiratory tract. Tracheostomy, apart from being invasive, is reported to spread the infection to the mediastinum [19]. Recently, conventional aggressive airway management evolved into a more conservative approach. Hassan et al declare conservative management acceptable in patients with normal oxygen saturation, respiratory rate on room air and no evident significant airway compromise on fiberoptic examination [18]. Several recent studies report successfully managed Ludwig angina patients with medical therapy as noted in most of the patients in this study [18-20]. In accordance with the "Practice Guidelines for Management of the Difficult Airway" of the American Society of Anaesthesiologists updated in 2003, Hasan et al recommend awake fiberoptic-assisted intubation then if this fails, a surgical tracheostomy in severely airway compromised patients defined as those unable to have saturation on room air above $95 \%$, those with respiratory rate above 25 or a significant airway compromise on fiberoptic laryngoscopy [18-21]. Newer advanced airway management techniques such as video-assissted laryngoscopy enable to decrease the need for tracheostomy [22]. Efficacy of intravenous steroids use as performed in this study for the airway management remains controversial as not demonstrated by randomized controlled trials [23-24]. Sepsis control commends broad spectrum antibiotic therapy and drainage of abscesses as well as surgical debridement of necrotic tissues. Antibiotics must be given early, at massive doses and intravenously. Most commonly antimicrobial agents recommended prior to the culture and sensitivity tests results include penicillin, clindamycin, and metronidazole understanding the role of Streptococcus and anaerobic germs [18-25]. Sepsis control includes also treatment of the infection origin. Treatment of carious tooth will consist frequently in its removal. Even when it is properly treated, Ludwig angina remains deadly with current estimates in the range of $8 \%$ [4-5]. As in any infection, physiological changes during pregnancy of which 
diminished immune response place the mother at a higher risk of death in Ludwig angina. Osunde et al report a maternal mortality rate of $20 \%$ in 10 patients [11]. Fetus is in a context of high vulnerability which may result in a diversity of adverse pregnancy outcomes including among other, intrauterine death, premature delivery, spontaneous abortion, low birth weight, intrauterine growth restriction, malformation, and neonatal infection [1]. In their study, Osunde et al report 3 fetal deaths [11]. Intra uterine death may result from consequences of the infection in the mother, fetal direct infection via the placenta damaging a vital organ such as the lung or heart of the fetus, the placenta infection resulting in a fatal congenital anomaly by reduced blood flow to the fetus, a preterm labor with the fetus unable to tolerate delivery, generally due to an infection of the membranes [26]. Consequences of the infection in the mother leading to fetal death include among other, high fever in mother, maternal poor oxygenation or systemic reaction deadly for the fetus. Establishing formally a causal association between a pregnancy adverse outcome and the infection is however challenging. To determine the cause of stillbirth, one of the major adverse pregnancy outcomes, more than 30 approaches are proposed in the literature [26-27]. Difficulty in establishing a causal association between a pregnancy adverse outcome and an infection comes from the existence of a diversity of potential causes. In the setting of this study, malaria is among the common of these causes as endemic. Its adverse effects on pregnancy which include stillbirth, abortion, low birth weight, prematurity, are directly related to the extent of placental malaria and partly to the degree of maternal anemia [28-29]. Bacterial infections such as pneumonia, tuberculosis, typhoid fever, and pyelonephritis and the human immunodeficiency virus (HIV) infection with its opportunist infections must also be mentioned. Additionally, infections such as asymptomatic bacteruria periodontal disease and abnormal vaginal flora have been recognized recently to potentially contribute to preterm labor and delivery [30-33]. In medically underserved setting, their impact on pregnancy is over looped as they are not routinely screened.

\section{Conclusion}

Threat of Ludwig angina in pregnancy for both the mother and the fetus commends oral health care providers to be aware of proper treatment of dental infections and also alert for early recognition and multidisciplinary management of this clinical entity in collaboration with obstetricians, specialists of intensive care and infectious diseases.

\section{References}

[1] Jeffery HE and Lahra MM (2009). The impact of infection during pregnancy on the mother and baby. DOI: $10.1007 / 978-$ 1-84628-743-5_16.

[2] Abramowicz S, Abramowicz JS and Dolwick MF (2006) Case
Report: Severe Life Threatening Maxillofacial Infection in Pregnancy Presented as Ludwig's Angina. Hindawi Infect Dis Obstet Gynecol 2006: 1-4.

[3] Kassam K Messiha A and Heliotis M. (2013) Ludwig's Angina: The Original Angina. Case Rep Surg doi: $10.1155 / 2013 / 974269$.

[4] Saifeldeen K and Evans R (2004) Ludwig's angina. Emerg Med J 21: 242-243.

[5] Bansal A, Miskoff J and Lis RJ (2003) Otolaryngologic critical care. Crit Care Clin 19: 55-72.

[6] World Health Organization (2004) A strategic framework for malaria prevention and control during pregnancy in the African region Brazzaville: WHO regional office for Africa.

[7] Kavarodi AM (2011) Necrotizing fasciitis in association with Ludwig's angina - A case report. The Saudi Dental Journal 23, 157-160.

[8] Medard de Chardon, V Guevara, N Lattes L, ConversetViethel S, Riah Y, Lebreton E, Santini J, and Balaguer T (2008) Necrotizing fasciitis: complication of patient positioning? Ann Chir Plast Esthet. 53 (4): 372-377.

[9] Jee HS, Won-Hee J, Kyung-Ah C, Ji-Young K, Chan-Kwon J, Yang RK, Wan-Kyu E, Yang-Soo K, and Yang GC, (2009) Necrotizing fasciitis versus pyomyositis: discrimination with using MR imaging. Korean J. Radiol. 10, 121-28.

[10] Pak S, Cha D, Meyer C, Dee C and Fershko A (2017) Ludwig's Angina. Cureus 9 (8): e1588. DOI 10.7759 /cureus. 1588 .

[11] Osunde OD, Bassey GO, Ver-or N (2014) Management of Ludwig's Angina in Pregnancy: A Review of 10 Cases. Ann Med Health Sci Res. 4 (3): 361-4. doi: 10.4103/21419248.133460 .

[12] Topazian RG, Goldberg MH and Hupp JR (2002): Oral and Maxillofacial infections. 4th ed. Philadelphia, Pa:W. B. Saunders.

[13] Botha A, Jacobs F and Postma C (2015) Retrospective analysis of etiology and comorbid diseases associated with Ludwig's Angina. Ann Maxillofac Surg 5 (2): 168-173.

[14] Peron JM and Mangez JF (2002) Cellulites et fistules d'origine dentaire Encycl Méd Chir (Editions Scientifiques et Médicales Elsevier SAS, Paris), Stomatologie/Odontologie 22-033-A-10, $14 \mathrm{p}$.

[15] Brook I (2007) Microbiology and principles of antimicrobial therapy for head and neck infections. Infect Dis Clin North Am, 21: 355-91.

[16] Rutkauskas JS (1999) Oral infection. Infect Dis Clin North Am 13: 757-923.

[17] Spitalnic SJ and Sucov A (1995) Ludwig's angina: case report and review. J Emerg Med 13: 499-503.

[18] Hasan W, Leonard D and Russell J (2011) Ludwig's Angina-A Controversial Surgical Emergency: How We Do It. Int J Otolaryngol. doi: 10.1155 .

[19] Bado F, Fleuridas G, Lockhart R, Chikhani L, FavreDauvergne E and Bertrand JC (1997) Cellulites cervicales diffuses, à propos de 15 cas. Rev Stomatol Chir Maxillofac 98: 266-268. 
[20] Larawin V, Naipao J and Dubey SP (2006) Head and neck space infections. Otolaryngology - Head and Neck Surgery 135 (6): 889-893.

[21] Caplan RA, Benumof JL, Berry FA, Blitt CD, Bode RH, Cheney FW, Connis RT, Guidry OF, Nickinovich DG and Ovassapian A. (2003) An updated report by the American Society of Anesthesiologists Task Force on management of the difficult airway. Anesthesiology 98 (5): 1269-1277.

[22] Al Harbi M, Thomas J, Khalil HN, Said HN, Wannous S, Abouras C, Al Harthi A and Dimitrou V (2016) Anesthetic Management of Advanced Stage Ludwig's Angina: A Case Report and Review With Emphasis on Compromised Airway Management. Middle East J Anaesthesiol 23 (6): 665-73.

[23] Freund B and Timon C (1992) Ludwig's angina: a place for steroid therapy in its management? Oral Health 82, 5: 23-25.

[24] Chueng K, Clinkard DJ, Enepekides D, Yousef Peerbaye Y, and Lin VY (2012) An Unusual Presentation of Ludwig's Angina Complicated by Cervical Necrotizing Fasciitis: A Case Report and Review of the Literature. Case Rep Otolaryngol doi: 10.1155/2012/931350

[25] Parhiscar A and Har-El G (2001) Deep neck abscess: a retrospective review of 210 cases. Ann Otol Rhinol Laryngol 110 (11): 1051-4.

[26] McClure EM, Dudley DJ and Goldenberg RL (2010) Infectious Causes of Stillbirth: A Clinical Perspective. Clin Obstet Gynecol. 53 (3): 635-645.
[27] Gordijn SJ, Korteweg FJ, Erwich JJ, Holm JP, van Diem MT, Bergman KA, and Timmer A (2009) A multi-layered approach for the analysis of perinatal mortality using different classification systems. Eur J Obstet Gynecol Reprod Biol 44: 99-104.

[28] Steketee R, Nahlen BL, Parise ME, and Menendez C (2001) The burden of malaria in pregnancy in malaria-endemic areas. Am J Trop Med Hyg 64S: 28-35.

[29] van Geertruyden J-P, Thomas F, Erhart A, and D'Alessandro $\mathrm{U}$ (2004) The contribution of malaria in pregnancy to perinatal mortality. Ann Trop Med Hyg 71 (2): 35-40.

[30] Smaill F (2001) Antibiotics for asymptomatic bacteruria in pregnancy. Cochrane Database of Systematic Reviews 2:CD000490.

[31] Offenbacher S, Katz V, Fertik G, Collins J, Boyd D, Maynor G, Mckaiq R and Beck J (1996) Periodontal infections as a possible risk factor for preterm low birth weight. J Periodontal 67: 1103-1113.

[32] Newnham J, Shub A, Jobe A, Bird PS, Ikeqami M, Nitsos I and Moss TJ. (2005): The effects of intra-amniotic injection of periodontopathic lipopolysaccharides in sheep. Am J Obstet Gynecol 193: 313-321.

[33] Kiss H, Petricevic L and Husslein P (2004) Prospective randomised controlled trial of an infection screening programme to reduce the rate of preterm delivery. BMJ 14; 329 (7462): 371. 